\title{
NEW RECORDS OF THE GENUS Miconchus (Mononchida, Anatonchidae) FOR VIETNAM NEMATODE FAUNA
}

\author{
Vu Thi Thanh Tam \\ ${ }^{1}$ Institute of Ecology and Biological Resources, VAST, Vietnam \\ ${ }^{2}$ Graduate University of Science and Technology, VAST, Vietnam
}

Received 24 February 2020, accepted 31 July 2020

\section{ABSTRACT}

Two species of the genus Miconchus, viz. M. dahousiensis and M. baeticus, were recorded for the first time in Vietnam. The two collected species from Tuyen Quang, Ha Giang and Bac Can Provinces were redescribed and illustrated.

Keywords: Taxonomy, free-living soil nematodes, natural conservation area.

Citation: Vu Thi Thanh Tam, 2020. New records of the genus Miconchus (Mononchida, Anatonchidae) for Vietnam nematode fauna. Academia Journal of Biology, 42(3): 7-14. https://doi.org/10.15625/2615-9023/v42n3.14847.

Corresponding author email: vtam7572@yahoo.com

(C2020 Vietnam Academy of Science and Technology (VAST) 


\section{INTRODUCTION}

The genus Miconchus (Anatonchidae, Miconchinae) is firstly elected by Andrassy (1958) as a new genus with four genera Brachonchulus, Cobbonchus, Granonchulus and Judonchulus, which belong to the family Mononchidae. Andrassy (1976) proposed the new subfamily Miconchinae including the genus Miconchus under the family Mononchidae. Then, this subfamily Miconchinae was moved to the family Anatonchidae by Khan et al., (1978) (Ahmad $\&$ Jairajipuri, 2010). The genus Miconchus is characterized by the same size and position of dorsal and subventral or ventrosublateral teeth (either one or two pairs), directed anteriorly and located nearly basal or midway in the buccal cavity and by a similar tail in both sexes.

Up to now, 41 species have been described in this genus worldwide (Ahmad \& Jairajipuri, 2010; Siddiqi, 2016): 7 species in Europe; 9 species in Asia including Far East, Korea, Japan, Malaysia, India and Thailand; 9 species in North America; 10 species in South America including El Salvador, Cuba, Ecuador, St Lucia and Columbia; 5 species in Afrika including Egypt, Nigeria, South Afrika and Zaire; 5 species in Australia, New Zealand, Papua New Guinea and Fiji islands. Miconchus dalhousiensis Jairajpuri, 1969 was reported only from India and Pakistan (Jairajipuri, 1969; Tabassum et al., 2001) and Miconchus baeticus Jiménez Guirado, Alhama \& Gutiérrez, 1997 was documented by its type population from Málaga, Spain (Jiménez Guirado et al., 1997).

Until now, six species of the genus Miconchus were recorded from some provinces in Vietnam including M. aquaticus Khan, Ahmad \& Jairajpuri, 1978, M. citri Khan, Ahmad \& Jairajpuri, 1978, M. digiturus Cobb, 1893, M. kansaensis Mulvey \& Dickerson, 1970, M. studeri Steiner, 1914 and $M$. triodontus Buangsowon \& Jensen, 1966 (Nguyen, 2005). However, the records of $M$. dalhousiensis and M. baeticus reported here are the first records for the nematode fauna in Vietnam.

\section{MATERIALS AND METHODS}

Soil samples were collected randomly around the base of trees from natural conservation areas, Cham Chu (Tuyen Quang Province), Du Gia (Ha Giang Province) and $\mathrm{Ba}$ Be National Park (Bac Kan Province), Vietnam. Nematodes were extracted from soil samples using a modified Baermann funnel technique (Southey, 1986). They were killed by heat, fixed in $4 \%$ formaldehyde, transferred to anhydrous glycerol (Seinhorst, 1959) and mounted on glass slides for microscopic observation. Photographs were taken with a Nikon digital camera connected to a Nikon Eclipse Ni microscope and edited using Adobe Photoshop CS6. Permanent slides were stored at the Department of Nematology, Institute of Ecology and Biological Resources, VAST, Ha Noi, Vietnam.

\section{RESULTS AND DISCUSSION}

\section{Miconchus dalhousiensis Jairajpuri, 1969}

Materials: two populations from natural conservation areas Cham Chu (Tuyen Quang Province) and $\mathrm{Du}$ Gia (Ha Giang Province) with 16 females in good condition. Measurements: see table 1.

Female: Body large size. Habitus after fixation slightly ventrally arcuate, particularly toward posterior end; tapering slightly anteriorly and more pronounced posteriorly. Cuticle smooth, 4.5-6 $\mu \mathrm{m}$ thick at the base of pharynx. Lip region 48-53 $\mu \mathrm{m}$ wide and 15-17 $\mu \mathrm{m}$ height, slightly offset and wider than adjacent body contour; slightly angularly head with anterior sensilla arranged in two circles $(6+10)$. Amphids small cup-like, aperture $6 \mu \mathrm{m}$ wide at $15-17 \mu \mathrm{m}$ from the anterior end or at beginning of buccal cavity. Buccal cavity large size, as length as 1.4-1.6 times its width, barrel shaped, narrowing at base; foramina present, its wall moderated sclerotized.

Dorsal tooth and ventrosublateral teeth large; similar in size and shape with sharp apex, pointing forward and clearly suprabasal. Apex of dorsal tooth situated in posterior half of buccal cavity, at $15-17 \mu \mathrm{m}$ or 
approximately $26-35 \%$ of cavity length from its base. Pharynx cylindrical, 410-570 $\mu \mathrm{m}$ long. Nerve ring located at 145.4-163.2 $\mu \mathrm{m}$ or $31-38 \%$ of the pharyngeal region measured from the anterior body end. Excretory-secretory pore is conspicuous with distinctly sclerotized terminal duct; situated just posterior to nerve ring at about 172.7-186.2 $\mu \mathrm{m}$ or $36-44 \%$ of pharynx length from anterior body end. Pharyngointestinal junction tubercles prominent. Cardia projects into intestinal lumen. Rectum straight almost equal to anal body width long i.e. $13-15 \mu \mathrm{m}$ long.

Table 1. Comparison of morphometric data of Miconchus dalhousiensis Jairajpuri, 1969

\begin{tabular}{|c|c|c|c|c|}
\hline \multirow{2}{*}{ Local } & \multicolumn{4}{|c|}{ Miconchus dalhousiensis } \\
\hline & \multicolumn{2}{|c|}{ Dalhousie, India } & \multicolumn{2}{|c|}{ Present paper } \\
\hline Characters & Holotype & Paratype & Ha Giang & Tuyen Quang \\
\hline $\mathrm{n}$ & 10 & 30 & 79 & 90 \\
\hline $\mathrm{L}(\mu \mathrm{m})$ & 2060 & $1890-2000$ & $1718-1927$ & $1727-1918$ \\
\hline $\mathrm{V}(\%)$ & 68 & $66-67$ & $64.6-66.7$ & $64.3-67.7$ \\
\hline $\mathrm{a}$ & 28 & $28-30$ & $25.4-27.5$ & $25.1-28.2$ \\
\hline $\mathrm{b}$ & 3.7 & $3.5-3.6$ & $3.8-4.1$ & $3.8-4.2$ \\
\hline c & 13 & $12-13$ & $13-14.7$ & $12.4-13.4$ \\
\hline$c^{\prime}$ & \multicolumn{2}{|c|}{$\leq 4 *$} & $3.3-3.9$ & $3.3-4$ \\
\hline Pharynx length $(\mu \mathrm{m})$ & $557 *$ & - & $418-490$ & $413-572$ \\
\hline $\begin{array}{l}\text { Position excretory pore of } \\
\text { pharyngeal region length }(\%)\end{array}$ & \multicolumn{2}{|c|}{$33-35^{*}$} & $35.9-39.2$ & $36-44.2$ \\
\hline $\begin{array}{l}\text { Position nerve-ring of pharynx } \\
\text { length }(\%)\end{array}$ & - & - & $31.4-34$ & $32-37.9$ \\
\hline Buccal cavity length $(\mu \mathrm{m})$ & \multicolumn{2}{|c|}{$54-56$} & $50-53$ & $46-52$ \\
\hline Buccal cavity width $(\mu \mathrm{m})$ & \multicolumn{2}{|c|}{$39-41$} & $33-36$ & $30-35$ \\
\hline $\begin{array}{l}\text { Position of tooth apex (\%) from } \\
\text { the base of buccal cavity }\end{array}$ & \multicolumn{2}{|c|}{$29.6-34 *$} & $26-30.8$ & $26.5-34.8$ \\
\hline G1 (\%) & - & - & $5.4-10.9$ & $9.3-12.4$ \\
\hline $\mathrm{G} 2(\%)$ & - & - & $5.1-9.8$ & $7.6-11.2$ \\
\hline Lip region height $(\mu \mathrm{m})$ & \multicolumn{2}{|c|}{$18-19$} & $15-17$ & $15-17$ \\
\hline Lip region width $(\mu \mathrm{m})$ & \multicolumn{2}{|c|}{$46-51$} & $48-51$ & $49-53$ \\
\hline Body width at pharynx base $(\mu \mathrm{m})$ & - & - & $62-65$ & $60-69$ \\
\hline Maximum body width $(\mu \mathrm{m})$ & - & - & $66-76$ & $66-72$ \\
\hline Anal body width $(\mu \mathrm{m})$ & - & - & $15-18$ & $16-17$ \\
\hline Vagina length $(\mu \mathrm{m})$ & - & - & $13-14$ & $14-17$ \\
\hline Rectum length $(\mu \mathrm{m})$ & \multicolumn{2}{|c|}{$23-28$} & $13-15$ & $13-16$ \\
\hline Tail length $(\mu \mathrm{m})$ & \multicolumn{2}{|c|}{$150-160$} & $123-141$ & $134-157$ \\
\hline
\end{tabular}

Notes: "-”: No information; *: Calculation from original description.

Reproductive system didelphicamphidelphic, both branches about equally developed with ovaries reflexed, sphincter at the oviduct-uterus connection not seen. The forward branch is slightly longer than posterior branch. Vulva transverse slit like. Uterus with one or two eggs in some cases with egg size $102-115 \times 45-54 \mu \mathrm{m}$. Vagina short, 13-17 $\mu \mathrm{m}$ long or about one-fourth of corresponding body width, surrounded by well-developed constrictor muscle with par refringens vaginae as two drop-like sclerotized pieces in optical section. 


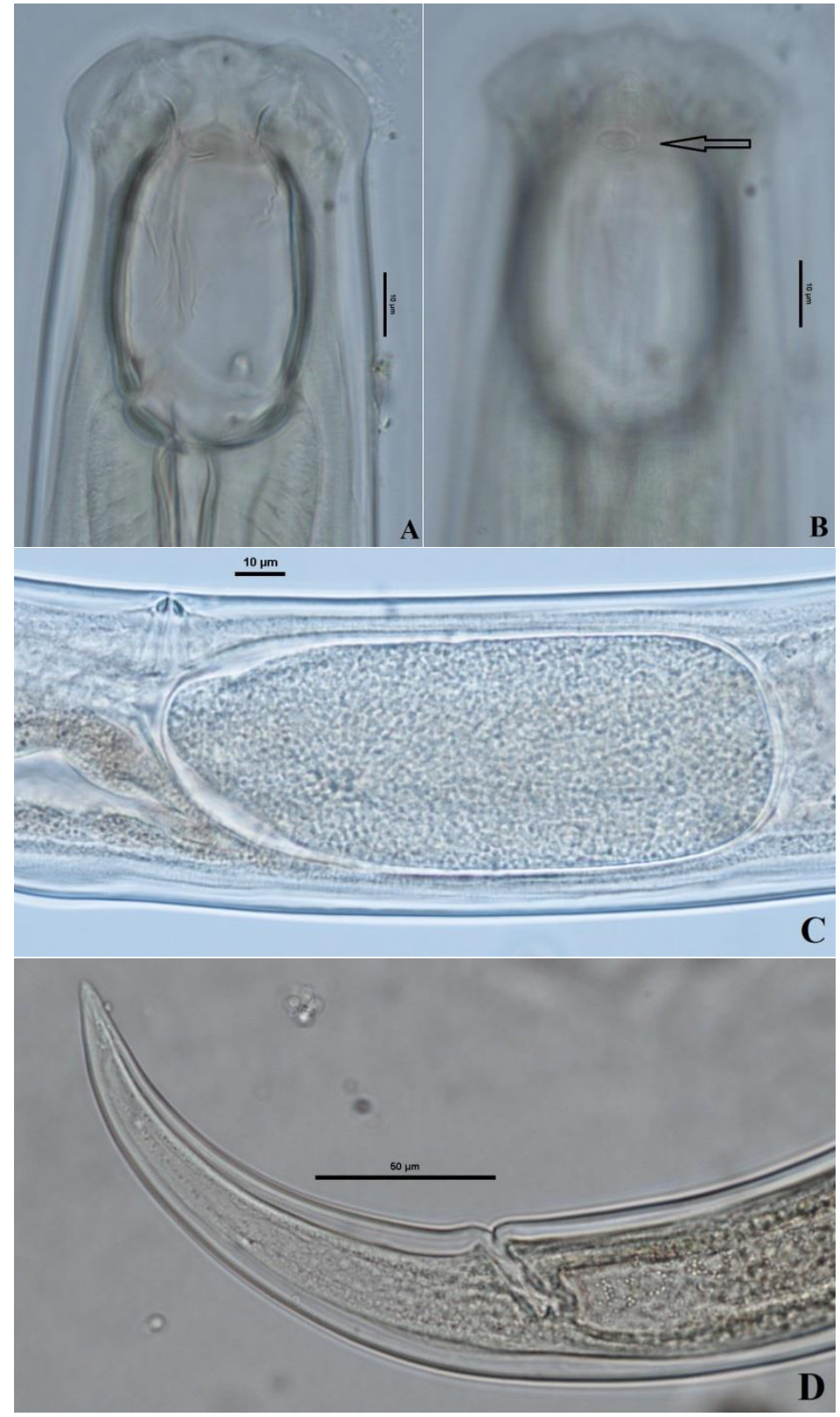

Figure 1. Miconchus dalhousiensis Jairajpuri, 1969

A. Head region; B. Amphid aperture; C: Vagina region; D. tail region

Tail elongated conoid with $130-157 \mu \mathrm{m}$ long, gradually tapering and ventrally curved. Caudal glands and spinneret absent.

Male: Not found.

Remarks: The measurements of Vietnamese specimens corresponded well with those of the holotype and paratype specimens from type population from Dalhousie, India (Jairajipuri, 1969) except for the slightly smaller size of buccal cavity (46-52 × 30-35 vs 50-53 × 33-36 $\mu \mathrm{m})$, lower lip height (15-17 vs 18-19 $\mu \mathrm{m})$ and shorter tail $(130-157$ vs $150-160 \mu \mathrm{m})$. The distribution of this species is not only the first time in Vietnam but also for Southeast Asia. 
Locality: Yen Thuan Commune (altitude at $900 \mathrm{~m}$ ), Cham Chu natural conservation area, Tuyen Quang Province and Minh Ngoc, Lac Nong Communes, Bac Me District (altitude at $700 \mathrm{~m}$ ), Du Gia natural conservation area, Ha Giang Province, Vietnam.

\section{Miconchus baeticus Jiménez-Guirado, Alhama \& Gutiérrez, 1997}

Materials: four females and three males in good condition were collected from $\mathrm{Ba} \mathrm{Be}$ National Park (Bac Can Province). Measurements: see table 2.

Table 2. Comparison of morphometric data of Miconchus baeticus Jiménez-Guirado, Alhama \& Gutiérrez, 1997

\begin{tabular}{|c|c|c|c|c|c|}
\hline Local & \multicolumn{5}{|c|}{ Miconchus baeticus } \\
\hline & \multicolumn{3}{|c|}{ Málaga, Spain } & \multicolumn{2}{|c|}{ Present paper } \\
\hline Characters & holotype & para & ypes & & \\
\hline $\mathrm{n}$ & 1 q & $20+$ & $12 \pi$ & 49 & $30^{\pi}$ \\
\hline $\mathrm{L}(\mathrm{mm})$ & 2.96 & $2.68-3.75$ & $2.45-3.28$ & $2.05-2.17$ & $1.93-2.15$ \\
\hline $\mathrm{V}(\%)$ & 65.7 & $61.6-66.9$ & - & $63.3-66.2$ & - \\
\hline $\mathrm{a}$ & 45 & $38.3-51.3$ & $37.6-53.2$ & $27-29$ & $29.6-32$ \\
\hline $\mathrm{b}$ & 4.8 & $4.4-5.3$ & $4.6-5.5$ & $4-4.3$ & $3.9-4.1$ \\
\hline $\mathrm{c}$ & 15.5 & $14.3-18.3$ & $17.2-21.7$ & $12-12.6$ & $13.5-14$ \\
\hline$c^{\prime}$ & 4.3 & $3.6-4.8$ & $2.5-3.2$ & $3.7-4.3$ & $3-3.2$ \\
\hline Pharynx length & 567 & $513.5-652$ & $475-659$ & $481-577$ & $463-531$ \\
\hline $\begin{array}{l}\text { Position excretory pore of } \\
\text { pharyngeal region length }(\%)\end{array}$ & $36.5^{*}$ & $34.9-37.1 *$ & $36.1-37.7 *$ & $34-39$ & $36-39$ \\
\hline $\begin{array}{l}\text { Position nerve-ring of } \\
\text { pharyngeal region length }(\%)\end{array}$ & $30.9^{*}$ & $26-$ & 3.3 & $33-34$ & $32.5-33.6$ \\
\hline Buccal cavity length $(\mu \mathrm{m})$ & 57 & $51-60$ & $50-55.5$ & $48-52$ & $47-48$ \\
\hline Buccal cavity width $(\mu \mathrm{m})$ & 37.5 & $33.5-39.5$ & $30.5-34$ & $29-31$ & $26-27$ \\
\hline $\begin{array}{l}\text { Position of tooth apex (\%) } \\
\text { from the base of buccal cavity }\end{array}$ & - & 31.5 & 41.7 & $38-42$ & $39-42$ \\
\hline $\mathrm{G} 1(\%)$ & 10.1 & $9-13.5$ & - & $11.7-14.9$ & - \\
\hline G2 (\%) & 9.7 & $8.9-12.2$ & - & $9.3-14$ & - \\
\hline Lip region height $(\mu \mathrm{m})$ & 13.5 & $14-20$ & $12.5-20$ & $14-17$ & $14-17$ \\
\hline Lip region width $(\mu \mathrm{m})$ & 45 & $45-55.5$ & $42-49.5$ & $43-47$ & $43-43$ \\
\hline $\begin{array}{l}\text { Body width at pharynx base } \\
(\mu \mathrm{m})\end{array}$ & - & - & - & $66-73$ & $48-50$ \\
\hline Maximum body width $(\mu \mathrm{m})$ & 65.5 & $57.5-82$ & $52-84$ & $72-89$ & $64-70$ \\
\hline Vagina length $(\mu \mathrm{m})$ & 23.5 & $17.5-28$ & - & $21-28$ & - \\
\hline Rectum length $(\mu \mathrm{m})$ & - & - & - & $29.5-38.6$ & - \\
\hline Tail length $(\mu \mathrm{m})$ & 191 & $166.5-209$ & $132.5-186$ & $166-173$ & $143-152$ \\
\hline Egg length $(\mu \mathrm{m})$ & - & 165.5 & - & $79-91$ & - \\
\hline Egg width $(\mu \mathrm{m})$ & - & 55.5 & - & $41-45$ & - \\
\hline Add vulva papillae & - & $0-3 / 0-3$ & - & $0-2 / 0-3$ & - \\
\hline Spicule length $(\mu \mathrm{m})$ & - & - & $80-105.5$ & - & $90-94$ \\
\hline Gubernaculum $(\mu \mathrm{m})$ & - & - & $18-26$ & - & $20-26$ \\
\hline Lat.guid.pieces $(\mu \mathrm{m})$ & - & - & $15-24.5$ & - & $15-15$ \\
\hline Supplement number & - & - & $13-16$ & - & $14-16$ \\
\hline
\end{tabular}

Notes: "-”: No information; *: Calculation from original description. 
Female: Body large size. Habitus after fixation straightly anteriorly and ventrally curved to J-shaped posteriorly. Cuticle smooth, 5-6 $\mu \mathrm{m}$ thick at the base of pharynx. Lip region 43-47 $\mu \mathrm{m}$ wide and 14-17 $\mu \mathrm{m}$ height, clearly offset and wider than adjacent body contour; rounded head with short anterior labial sensilla and cephalic. Amphids small cup-like, aperture 5-6 $\mu \mathrm{m}$ wide at just behind of the beginning of buccal cavity. Buccal cavity large size, with 48-52 $\mu \mathrm{m}$ long and 29-31 $\mu \mathrm{m}$ wide or as length as 1.6-1.8 times its width, barrel shaped, narrowing at base and thick walls, foramina present.

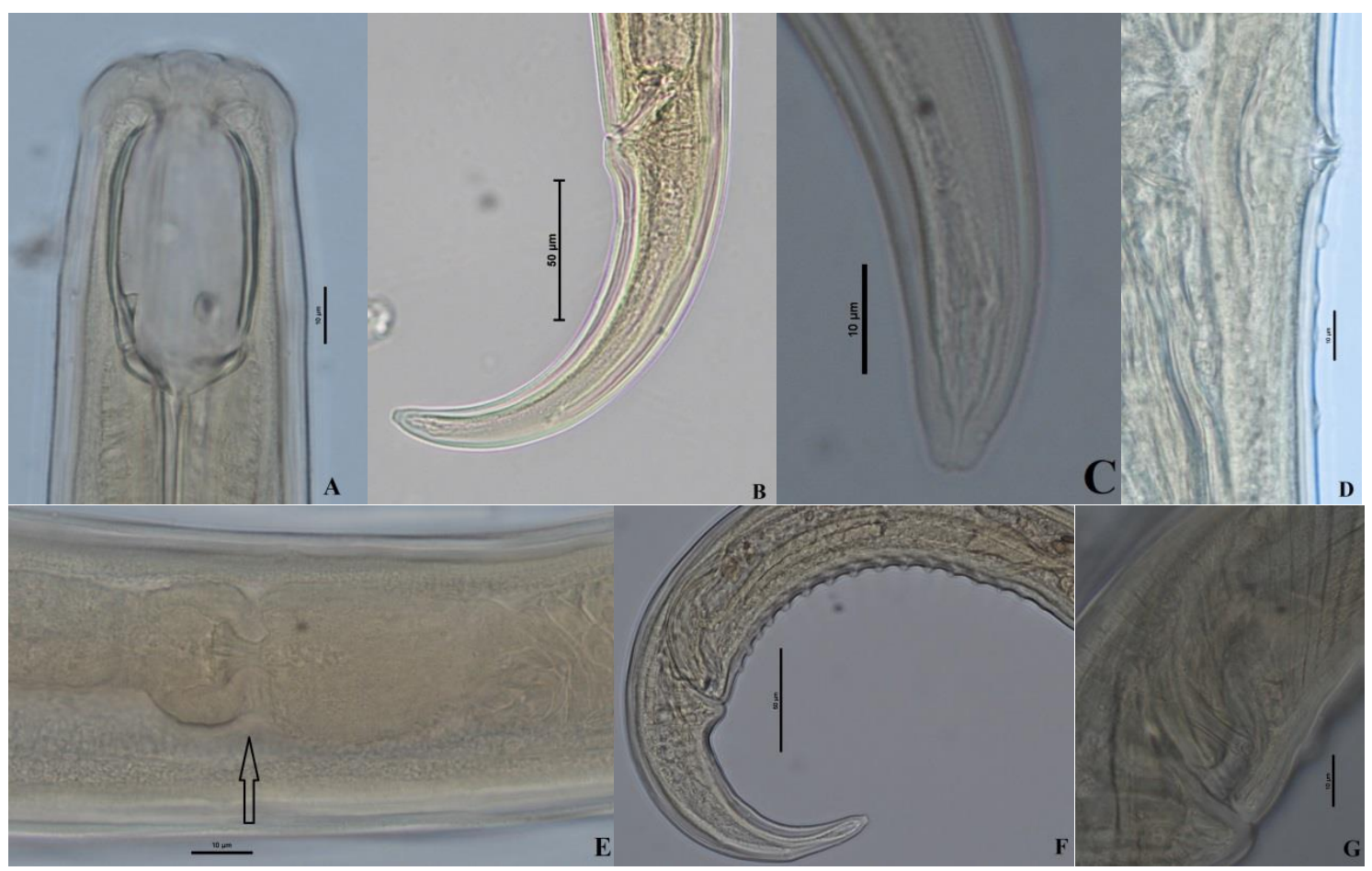

Figure 2. Miconchus baeticus Jiménez-Guirado, Alhama \& Gutiérrez, 1997

A. Female head region; B. Female tail region; C. Female tail terminus; D. Advulval papillae; E. Sphincter; F. Male tail region; G. Accessory piece

Dorsal tooth and ventral-sublateral teeth large, similar in size and shape with sharp apex, forward directed Apex of dorsal tooth situated in posterior half of buccal cavity, at $38-42 \%$ its length measured from the base. Pharynx cylindrical and muscular, 481-577 $\mu \mathrm{m}$ long. Nerve ring located at the level $181.3-200.8 \mu \mathrm{m}$ or $33-34 \%$ of pharyngeal region from anterior. Secretory-excretory pore small but clearly visible, situated just posterior to nerve ring, about $208.8-221 \mu \mathrm{m}$ or $34-39 \%$ of its length from anterior body end. Pharyngo-intestinal junction tuberculate and tubercles prominent. Rectum straight, thickwalled, 29.5-38.5 $\mu \mathrm{m}$ long.
Genital system didelphic-amphidelphic, both branches about equally developed with ovaries shorted and reflexed, large sphincter at the oviduct and uterus junction clearly visible. The anterior genital branch slightly longer than posterior branch. Vulva a short transverse slit. Advulval papillae well developed, 0-2 papillae anterior and 2-3 posterior to vulva. Vagina short, 21-28 $\mu \mathrm{m}$ long or about one-third of corresponding body width, surrounded by well-developed constrictor muscle with par refringens vaginae visible as two rounded triangular or dot like sclerotized pieces in optical section. 
Tail elongate conoid, ventrally curve, 166-173 $\mu \mathrm{m}$ long. Terminus sub-truncate. Caudal glands well developed with a common duct expanding to apparently form an ampulla. Terminal spinneret present.

Male: Similar to female in morphology and body size, posterior part of body more ventrally arcuate. Genital system diorchic; testes opposed, elongated. Spicule moderate slender, ventrally curved and 90-94 $\mu \mathrm{m}$ long. Gubernaculum developed and 20-26 $\mu \mathrm{m}$ long; lateral guiding pieces $15 \mu \mathrm{m}$ long with bifurcate tips. 14-16 ventromedian supplements present and more or less regularly spaced.

Remarks: The morphology and measurements of Vietnamese specimens corresponded well with those of the holotype and paratype specimens from type population from Sierra de las Nieves, Ronda, Province of Málaga, Spain (Jiménez-Guirado, 1997) except for a shorter body size (1.93-2.17 vs 2.68-3.75 mm), smaller size of buccal cavity $(48-52 \times 29-31$ vs $51-60 \times 33-39 \mu \mathrm{m})$ and lower in "c" ratio (12-13 vs 14-18); the latter can be explained by longer body size. Málaga Province is located in the southern Spain and lies about $130 \mathrm{~km}$ to the north of Africa with the climate is subtropicalMediterranean, where the climate is very similar to that of Vietnam. The distribution of this species reported here is also not only the first time in Vietnam but also for Southeast Asia.

Locality: Ba Be National Park (altitude at 700 m), Bac Can Province, Vietnam.

In current paper, 8 species of the genus Miconchus have been recorded in Vietnam. The following adapted key to species is based on Ahmad \& Jairajpuri (2010):

1a Female mono-prodelphic.............................................................

1b Female didelphic-amphidelphic.................................................

2a Post-uterus sac as long as one body width..................................... digiturus

2b Post-uterus sac ca 2 times the body width................................... triodontus

3a Ventral-sublateral teeth originating very end of lateral wall.............................

$3 \mathrm{~b}$ Ventral-sublateral teeth in position or further anterior to midway in buccal

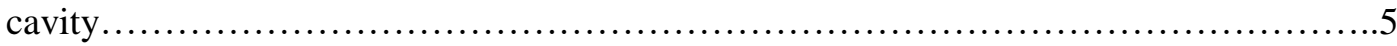

4a Caudal spinneret present, male known......................................... studeri

4b Caudal spinneret absent, male unknown......................................... citri

5a Apices of dorsal and ventral-sublateral teeth at midway of buccal cavity....... kansasensis

$5 \mathrm{~b}$ Apices of dorsal and ventral-sublateral teeth at 30-40\% of buccal cavity from the its

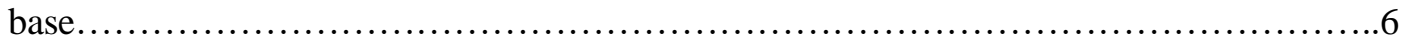

6a Caudal spinneret absent, male unknown, advulval papillae absent........... dalhousiensis

6b Caudal spinneret present, advulval papillae present, male known.........................

7a Buccal cavity large size 48-52 × 29-31 $\mu \mathrm{m} ; 0-3$ anterior advulval papillae and 0-3 posterior; male with 13-16 supplements. M. baeticus

7b Buccal cavity large size 43-48 × 29-31 $\mu \mathrm{m} ; 5-7$ anterior advulval papillae well developed and $0-1$ weak posterior one; male with $17-21$ supplements M. aquaticus

Acknowledgements: This work is partly supported by the project "The NEF Bioecological Nature Conservation Project in
Mountainous Region of North Vietnam" funded by Nagao Environmental Foundation, Japan. 


\section{REFERENCES}

Ahmad W., Jairajpuri M. S., 2010. Mononchida: The predaceous nematodes. Brill Leiden-Boston. 298 pp.

Jairajpuri M. S., 1969. Studies on Mononchida of India. I. The genera Hadronchus, Iotonchus and Miconchus and a revised classification of Mononchida, new order. Nematologica, 15: 557-581.

Jiménez-Guirado D., Alhama J. C., Gutierrez M. D. G., 1997. Mononchid nematodes from Spain. Six known species and Miconchus baeticus sp.n. occurring in southern fir forests. Fundamental and Application Nematology, 20(4): 371-383.

Nguyen V. T, 2007. Fauna of Vietnam. No 22. Free living nematodes: Monhysterida, Araeolaimida, Chromadorida, Rhabditida, Enoplida, Mononchida, Dorylaimida.
Science and Technics Publishing House. 455 pp. (in Vietnamese).

Seinhorst J. W., 1959. A rapid method for the transfer of nematodes from fixative to anhydrous glycerin. Nematologica, Vol. 4 (1): 67-69.

Siddiqi M. R., 2016. Descriptions of seven new species of the nematode genus Miconchus Andrassy, 1958 (Mononchida). International Journal of Nematology, 25(2): 145-165.

Southey J. F., 1986. Laboratory methods for work with plant and soil nematodes. London: Her Majesty' Stationery Office. 202 pp.

Tabassum K. A., Shanina F., Shaukat S. S., 2001. Three new records of the order Mononchida (Enoplida: Nematoda) from Pakistan. Pakistan journal of Nematology, 19(1\&2): 41-47. 